$\mathrm{DE}$

M E D I C I N A

T R O P I C A L

$\mathrm{DE}$

S ÃO PAULO

JOURNAL OF THE SÃO PAULO INSTITUTE OF TROPICAL MEDICINE

'Universidade Federal do Estado do Rio de Janeiro, Centro de Ciências Biológicas e da Saúde, Hospital Universitário Gaffrée e Guinle, $10^{a}$ Enfermaria, Rio de Janeiro, Rio de Janeiro, Brazil

${ }^{2}$ Universidade Federal do Estado do Rio de Janeiro, Centro de Ciências Biológicas e da Saúde, Hospital Universitário Gaffrée e Guinle, Serviço de Anatomia Patológica, Rio de Janeiro, Rio de Janeiro, Brazil

*The first two authors contributed equally to the study.

Correspondence to: Walter de Araujo Eyer-Silva

Universidade Federal do Estado do Rio de Janeiro - Hospital Universitário Gaffrée e Guinle, $10^{a}$ Enfermaria, Rua Mariz e Barros, 775, CEP 22290-240, Rio de Janeiro, RJ, Brazil

E-mail: walter.eyer@ig.com.br

Received: 8 December 2018

Accepted: 2 January 2019

\section{Gastric cryptococcosis: an unusual presentation of a common opportunistic disorder}

Rio de Janeiro, November $25^{\text {th }}, 2018$

Dear Editor

Cryptococcosis can frequently complicate the course of the acquired immunodeficiency syndrome, and cryptococcal meningoencephalitis is by far its main clinical presentation ${ }^{1}$. In fact, the organism is ubiquitous in soil and dust and is acquired by the inhalation of infectious propagules from the environment ${ }^{1}$. Other sites of extraneural involvement include the joints, oral cavity, pericardium, skin, mediastinum and genitourinary tract ${ }^{1}$.

The stomach is rarely the site of an opportunistic infection so that gastric cryptococcosis is an extremely rare complication. However, it may be the first clinical presentation of $\operatorname{AIDS}^{2,3}$. Gastric or gastrointestinal cryptococcosis may be clinically silent or present with nonspecific symptoms frequently attributable to other more prevalent disorders. We present a case of gastric cryptococcosis in an AIDS patient who had concomitant cryptococcal meningoencephalitis and disseminated Kaposi's sarcoma.

A 34 year-old African-Brazilian male patient presented with a 2-month history of epigastralgia, nauseas and vomiting that progressed within a few weeks to persistent headaches. The patient had a diagnosis of HIV infection made 6 years before and was non-adherent to the antiretroviral treatment. Within the last few months, multiple cutaneous lesions of Kaposi's sarcoma had developed (confirmed by biopsy). The CD4 cell count was $10 / \mathrm{mm}^{3}$ and the plasma HIV viral load was 74,411 copies $/ \mathrm{mL}$ ( $4.8 \mathrm{log}$ ). Cerebrospinal fluid examination yielded a diagnosis of cryptococcal meningitis through direct examination and fungal culture. Esophagogastroduodenoscopy disclosed raised reddened lesions over the body of the stomach, some of which had a central ulceration. There were also two reddened, flattened lesions in the antrum and one lesion in gastric fundus. Histopathologic analyses of biopsy samples revealed a diagnosis of gastric cryptococcosis (Figure 1). There was no histopathological evidence of gastric Kaposi's sarcoma. Treatment was initiated with amphotericin B deoxycholate, as well as prophylaxis of other opportunistic infections, but the patient eventually died of respiratory failure four weeks after admission.

The clinical presentation of gastric cryptococcosis has been described as symptoms of "gastroesophageal reflux including odynophagia"4, "epigastric abdominal pain and biliary vomiting", "odynophagia and intractable vomiting"3, "acute worsening of chronic watery diarrhea with melena" 6 and "chronic dysphagia with epigastralgia"”.

Intraabdominal cryptococcosis at sites other than the stomach has been reported in the esophagus, duodenum, jejunum, ileum, colon and the gallbladder ${ }^{4,8-12}$. It may present as cryptococcal peritonitis ${ }^{8}$, as an acute abdomen due to jejunal perforation ${ }^{9}$, as an acute appendicitis in a case of mesenteric cryptococcal lymphadenitis ${ }^{10}$, as epigastric discomfort, early satiety and abdominal distention in a case of duodenal cryptoccoccosis $^{11}$, and as a retroperitoneal cryptococcoma mimicking a pancreatic tumor $^{12}$.

Endoscopic and macroscopic pathologic findings of gastric cryptococcosis have been described as lesions of yellowish granular appearance ${ }^{13}$, as nodules ${ }^{4}$, as nodules with central erosions resembling inflammatory polyps ${ }^{2}$, as a circumscribed lesion 


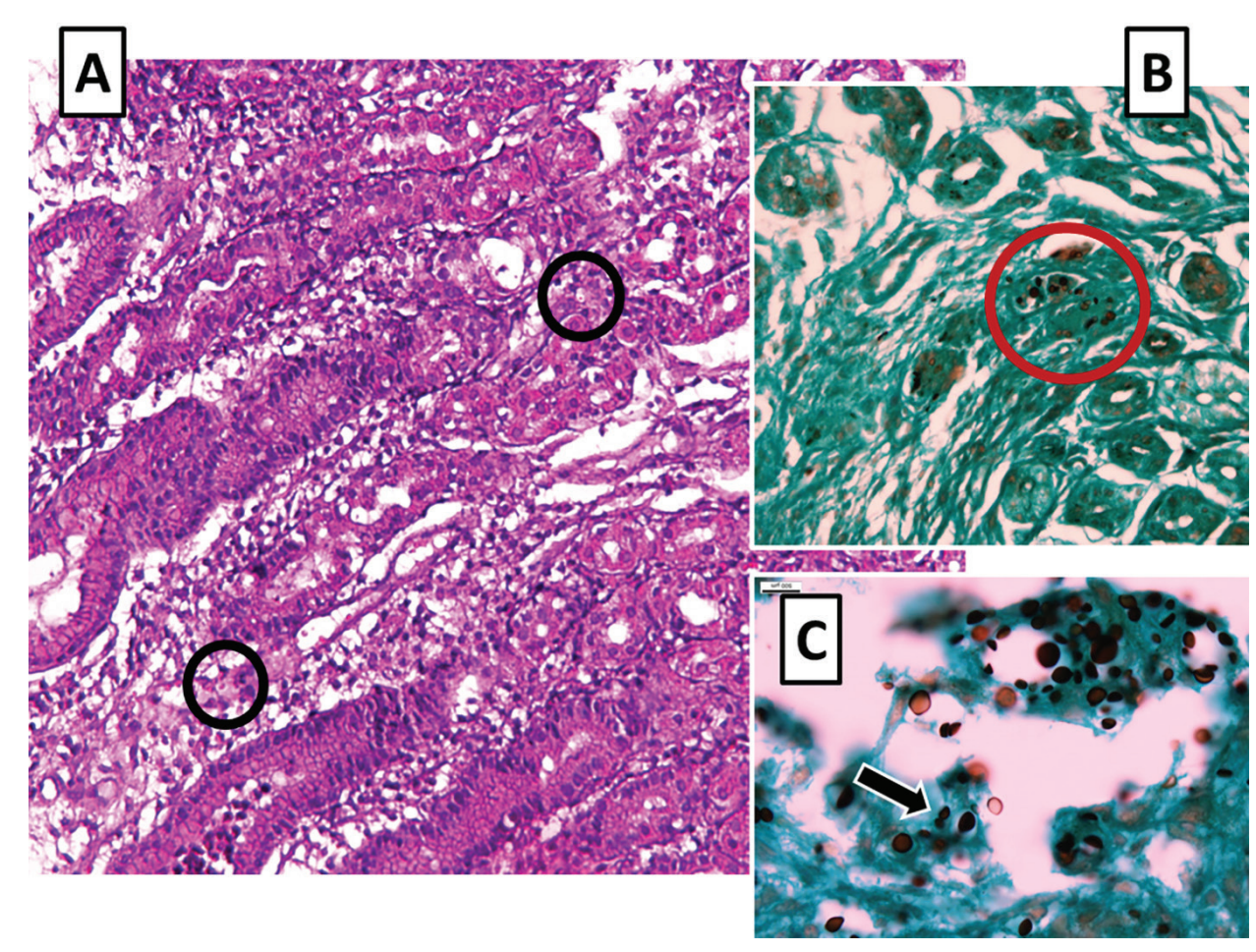

Figure 1 - A) Hematoxylin and eosin staining (original magnification $200 \mathrm{x}$ ) discloses oxyntic glands in the body of the stomach with marked edema and a lymphoplasmacytic inflammatory reaction of the lamina propria. Extracellular varied-sized round structures with a halo clearing around each organism are seen (black circles); B) Grocott methenamine silver (GMS) staining (original magnification 200 x) unmasks variable-sized yeast-like structures (red circle); C) Higher resolution (original magnification 400 x) GMS staining shows some organisms with a narrow-based budding (arrow) consistent with Cryptococcus spp.

with central umbilication ${ }^{2}$, as circumscribed nodules, some having central erosions resembling inflammatory polyps ${ }^{2}$, as irregular gastric ulcers, occasionally with red-pigmented lesions within the ulcer ${ }^{6}$ and as gastric erosions ${ }^{3}$.

It has also been suggested that some cases of gastrointestinal cryptococcosis may be a manifestation of the immune reconstitution inflammatory syndrome (IRIS). Musubire et $a l .{ }^{14}$ reported the case of a 37 year-old HIVinfected man with a history of cryptococcal meningitis who presented with subacute, worsening abdominal pain and abdominal lymphadenopathy during immune recovery. He was initially treated for presumed abdominal tuberculosis, but subsequently developed a perforation of the ileum requiring bowel resection. Histopathology confirmed a cryptococcoma of the ileum ${ }^{14}$. Moreover, Ferraioli et al $^{12}$ reported the case of a 50-year-old HIV-infected woman who presented with low-grade fever and abdominal pain due to a retroperitoneal cryptococcoma 15 months after being diagnosed with cryptococcal meningitis.

Our patient had a very low CD4 cell count and developed gastric cryptococcosis associated with cryptococcal meningoencephalitis. AIDS patients with gastrointestinal cryptococcosis generally have an exceedingly low CD4 cell count. Most reported cases had less than $50 \mathrm{CD} 4$ cells $/ \mathrm{mm}^{3,10-12,14}$ and concomitant cryptococcal meningoencephalitis is also common ${ }^{2,5-7,10,11}$, but some patients apparently had no evidence of neurologic disease $^{3,8,9}$. Esophagogastroduodenoscopy followed by histopathology of biopsy samples have proved to be an invaluable diagnostic tool ${ }^{2-7,11}$.

In summary, gastric and gastrointestinal cryptococcosis is generally a complication of advanced AIDS in patients with severe CD4 cell depletion. It may present as an acute abdominal episode or with nonspecific chronic symptoms. Therefore, it requires a high index of suspicion. Endoscopic studies and appropriate histopathological analyses are of utmost importance to the diagnosis. The present case seems to emphasize that physicians should constantly exercise a high index of suspicion of uncommon presentations of common opportunistic infections in AIDS patients.

Walter de Araujo Eyer-Silva ${ }^{1 *}$ Thaynny Cândida de Oliveira ${ }^{1 *}$

Ricardo de Souza Carvalho ${ }^{1}$ Isabelle de Carvalho-Rangel ${ }^{1}$ Rodrigo Panno Basílio-de-Oliveira ${ }^{2}$ Luciana Ferreira de Araujo $^{2}$ Guilherme Almeida Rosa da Silva ${ }^{1}$ Rogério Neves-Motta ${ }^{1}$ 


\section{CONFLICT OF INTERESTS}

The authors declare there is no conflict of interest.

\section{INFORMED CONSENT}

The informed consent of the patient was obtained for publication of the case.

\section{REFERENCES}

1. Page KR, Chaisson RE, Sande M. Cryptococcosis and other fungal infections (histoplasmosis and coccidioidomycosis) in HIV-infected patients. In: Volberding PA, Greene WC, Lange JM, Gallant JE, Sewankambo N, editors. Sande's HIV/AIDS medicine: medical management of AIDS 2013. Amsterdam: Elsevier; 2012. p.369-88.

2. Chalasani N, Wilcox CM, Hunter HT, Schwartz DA. Endoscopic features of gastroduodenal cryptococcosis in AIDS. Gastrointest Endosc. 1997;45:315-7.

3. Sundar R, Rao L, Vasudevan G, Gowda PB, Radhakrishna RN. Gastric cryptococcal infection as an initial presentation of AIDS: a rare case report. Asian Pac J Trop Med. 2011;4:79-80.

4. Washington K, Gottfried MR, Wilson ML. Gastrointestinal cryptococcosis. Mod Pathol. 1991;4:707-11.

5. Giradin M, Greloz V, Hadengue A. Cryptococcal gastroduodenitis: a rare location of the disease. Clin Gastroenterol Hepatol. 2010;8:e28-9.

6. Liu Y, Patel AA, Shaw JC, Fillman EP, Lamb PB. Gastroduodenal cryptococcus in an AIDS patient presenting with melena. Gastroenterology Res. 2013;6:26-8.
7. Roig-Rico P, Delgado-Sánchez E, Marín-Tordera D, ChuliaGómez MT, Mayol-Belda MJ, Martínez-Egea A. Criptococosis gástrica en paciente VIH. Rev Med Chile. 2014;142:932-3.

8. Stiefel P, Pamies E, Miranda ML, Martin-Sanz MV, FernandezMoyano A, Villar J. Cryptococcal peritonitis: report of a case and review of the literature. Hepatogastroenterology. 1999;46:1618-22.

9. Saha S, Agarwal N, Srivastava A, Kumar A. Perforation peritonitis due to gastrointestinal cryptococcosis as an initial presentation in an AIDS patient. Singapore Med J. 2008;49:e305-7.

10. Tapia O, Villaseca M, Araya JC. Linfoadenitis criptococócica mesentérica: una rara causa de abdomen agudo. Caso clínico. Rev Med Chile. 2010;138:1535-8.

11. León M, Alave J, Martinez D, Bustamante B, Rodriguez M, Seas C. Symptomatic duodenal cryptococcosis in HIV-infected individuals. Med Mycol. 2011;49:775-8.

12. Ferraioli G, Cavanna C, Ricciardi M, Daffara S, Sangiovanni L, Filice C, et al. Retroperitoneal cryptococcoma in a case of disseminated cryptococcosis on antifungal maintenance therapy. Curr HIV Res. 2011;9:28-30.

13. Bonacini M, Nussbaum J, Ahluwalia C. Gastrointestinal, hepatic, and pancreatic involvement with Cryptococcus neoformans in AIDS. J Clin Gastroenterol. 1990;12:295-7.

14. Musubire AK, Meya DB, Lukande R, Kambugu A, Bohjanen PR, Boulware DR. Gastrointestinal cryptococcoma - Immune reconstitution inflammatory syndrome or cryptococcal relapse in a patient with AIDS? Med Mycol Case Rep. 2015;8:40-3. 